\title{
The World Journal of Surgery is Pleased to Announce that Dr. Michelle de Oliveira Will Join Our Editorial Team as Our Associate Editor for Liver Surgery
}

\author{
Julie Ann Sosa ${ }^{1}$
}

Accepted: 22 September 2021/Published online: 6 October 2021

(C) Société Internationale de Chirurgie 2021

Dr De Oliveira qualified from the University Federal of Para in 1996. She pursued her surgical training in Sao Paulo-Brazil followed by a PhD degree. Dr De Oliveira moved overseas, obtaining a research fellowship at the Department of Surgery of Johns Hopkins in the USA and was recognized by UNESCO, representing Women in Science from Latin America. She moved to Switzerland for further research collaborations and undertook a clinical fellowship in hepato-pancreato-biliary surgery at the Swiss Hepato-pancreato-biliary \& Transplant Center at the University Hospital Zurich. She was appointed as a consultant surgeon in the HPB \& Liver Transplant Unit at the University Hospital of Zurich in 2011 after being qualified by the European Union of Medical Specialists (UEMS) and awarded with a Clinical Assistant Professor position at the University of Zurich in 2011.

Dr De Oliveira's clinical and research interests are in HPB surgery, liver transplant surgery and in topics related to women in surgery. She has published many landmark papers and written many book chapters. She has been awarded several prestigious grants, prizes and travelling fellowships and has given a number of eponymous lectures. Dr De Oliveira has a significant interest in medical education and training. She is currently the President of the UEMS (Union Eurpeenne des Medecins SpecilistesEuropean Union of Medical Specialists) HPB Surgery Board and Vice-Chair of the UEMS HPB Surgery Division

Julie Ann Sosa, MD, MA, FACS—Editor in Chief, World Journal of Surgery.

Julie Ann Sosa

julie.sosa@ucsf.edu

1 University of California San Francisco (UCSF),

San Francisco, CA, USA
(2019- present). Dr. De Oliveira is a council member of the of the European-African Hepato-Pancreatico-Biliary Association (E-AHPBA), member of the E- AHPBA Education Committee, and a member of the working group of HPB Women in Surgery of the E-AHPBA. She is also a member of the Education Committee of the International Hepato-Pancreato-Biliary Association (IHPBA) and member of the American College of Surgeons and Association of Women in Surgery.

Dr De Oliveira will be replacing Dr Olivier Soubrane, who will be rotating off the WJS editorial board after having faithfully served as associate editor during the pandemic. Thank you, Olivier, and welcome Michelle!

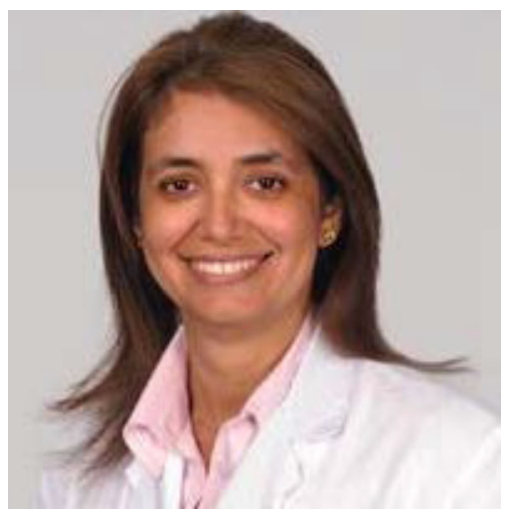

Publisher's Note Springer Nature remains neutral with regard to jurisdictional claims in published maps and institutional affiliations. 